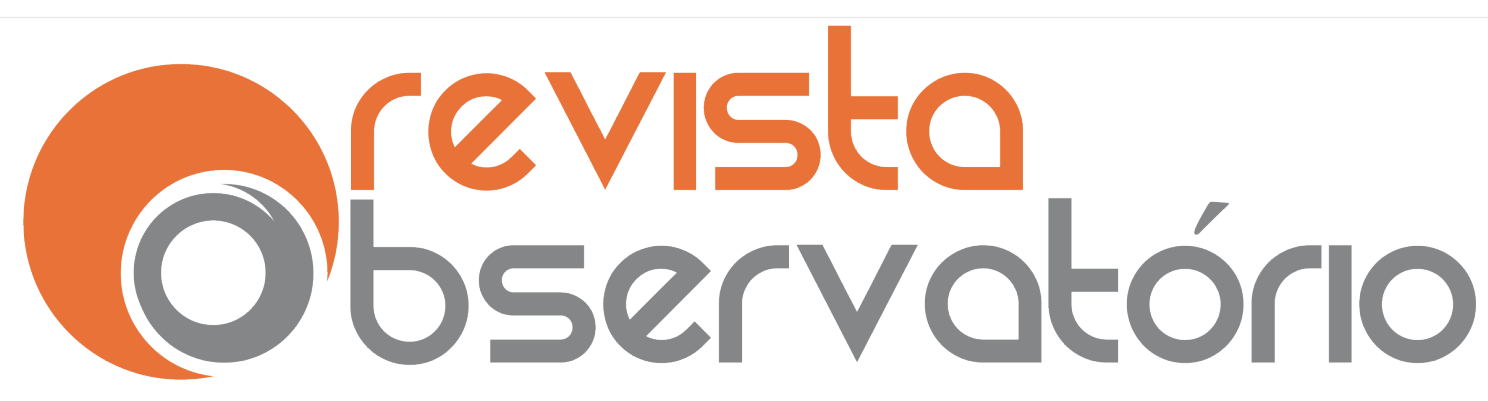

ISSN n० 2447-4266

Vol. 3, n. 3, Maio. 2017

DOI: http://dx.doi.org/10.20873/uft.2447-4266.2017v3n3p24

\title{
TECNOLOGIA E NARRATIVAS DIGITAIS: por entre caminhos
}

Se já não existe muita novidade em afirmar que o ambiente digital tem produzido aceleradas transformações na sociedade contemporânea, é necessário avançar no sentido de compreender como se dá essa mudança, que vetores a conduzem e que impactos gera na complexa teia das atividades humanas.

No campo da Comunicação, a produção de sentido estruturada através da asséptica lógica binária, que organiza o fluxo de informações circulando em redes e sistemas telemáticos, constitui-se em desafio para pesquisadores que, por tradição, foram treinados dentro do projeto crítico-descritivo das Humanidades, pouco aberto a se debruçar sobre números, ferramentas de software, planilhas, códigos de programação e, principalmente, sobre o enorme volume de dados hoje disponíveis nas redes digitais, fatores que, gostemos ou não, impactam fortemente a essência de todo o conteúdo gerado nesse ambiente.

Mesmo assim, iniciativas calcadas na interdisciplinaridade através de conexões com outros campos tais como os Estudos da Cognição, a Ciência da Computação, as Teorias de Redes, a Difusão de Inovações e a Filosofia da Tecnologia apresentam resultados promissores, constituindo-se em novos mapas para orientar cientistas que aceitam o desafio de explorar o complexo ecossistema dos meios nos dias de hoje.

Foi com esse intuito que em 2015 criamos o grupo de estudos em Tecnologia e Narrativas Digitais focado em incluir na agenda epistemológica da Comunicação um traço experimental e aplicado, utilizando a proposta da Design Science, ou seja, um tipo de ciência orientada pelo rigor científico mas também pela relevância social e coletiva dos seus trabalhos, direcionados à solução de problemas e desenvolvimento de artefatos para utilização de forma objetiva. Tal projeto 


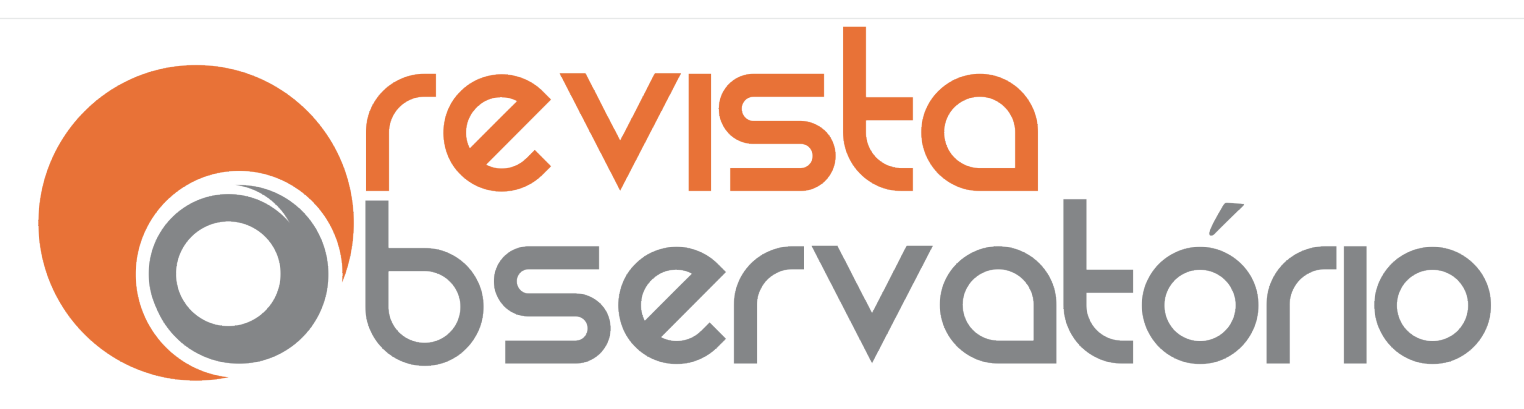

ISSN n² 2447-4266

Vol. 3, n. 3, Maio. 2017

DOI: http://dx.doi.org/10.20873/uft.2447-4266.2017v3n3p24

pretende atravessar os muros da academia para estabelecer um diálogo com a sociedade, vista não apenas como objeto de interpretação subjetiva mas também base física onde o conhecimento é testado, moldado e depurado, numa relação como a que o artífice estabelece com o material com que trabalha, ou nos termos de Sennett, na fusão entre a mão e o cérebro, capaz de gerar um tipo de aprendizado muito mais efetivo e transformador.

Com esse intuito, o presente dossiê proposto à Revista Observatório aglutina alguns textos que demonstram o enorme conjunto de possibilidades de investigação hoje disponíveis para as Ciências Sociais Aplicadas, passando pelas Humanidades que olham para o ambiente digital (Digital Humanities) e para a Comunicação em especial, principalmente quando abre pontes de contato com outras tradições da ciência.

É o caso do texto do professor Walter Lima Jr. intitulado DESAFIOS DO JORNALISMO EM AMBIENTE COMUNICACIONAL SIMBIÓTICO ESTRUTURADO PELA COMPUTAÇÃO COGNITIVA que analisa as transformações do jornalismo sob a ótica da Ciência Cognitiva e da interação homemmáquina numa abordagem inovadora que amplia os parâmetros de discussão do tema.

Softwares e sistemas inteligentes aplicados à atividade profissional da Comunicação são objeto de vários textos que tem como foco a narrativa jornalística. No texto JORNALISMO AUTOMATIZADO, GERAÇÃO DE LINGUAGEM NATURAL E A LÓGICA DO BOM SUFICIENTE doS pesquisadores Sebastião Squirra e Krishma Carrera, o polêmico assunto do jornalismo automatizado é visto não apenas pelo aspecto tecnológico mas também observando seus impactos sobre o mercado de trabalho e ainda sobre a ética jornalística.

No texto seguinte intitulado INTERNET DAS COISAS E SISTEMAS INTELIGENTES NO JORNALISMO: Explorando novas formas narrativas para reinventar a percepção de valor das novas gerações, Marcio Carneiro dos Santos, dentro do espírito da Design Science, explica a proposta desse tipo de abordagem científica, problematizando seu papel dentro dos estudos da 


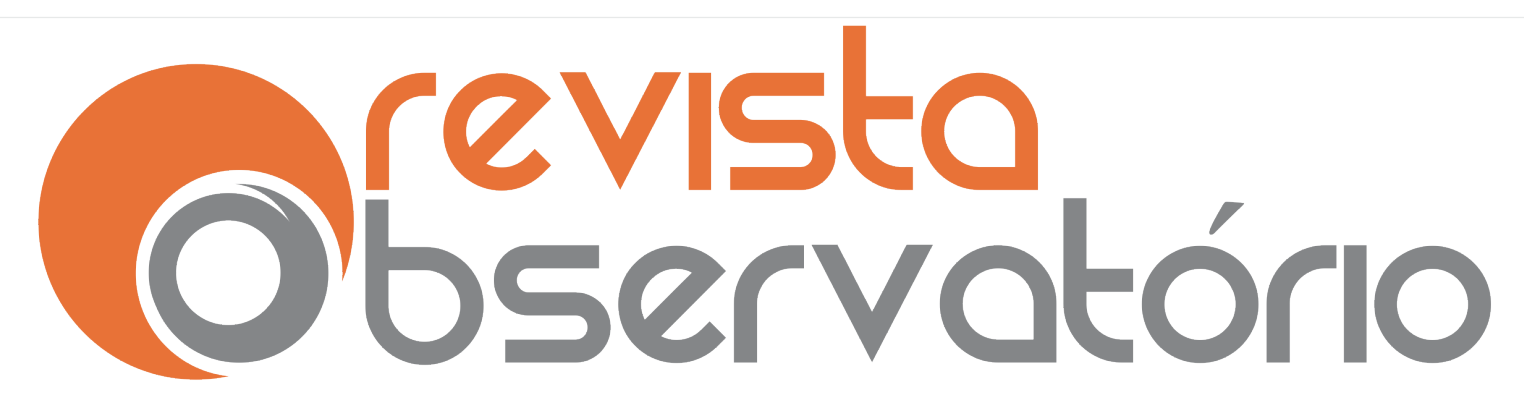

ISSN n² 2447-4266

Vol. 3, n. 3, Maio. 2017

DOI: http://dx.doi.org/10.20873/uft.2447-4266.2017v3n3p24

Comunicação e relatando um experimento aplicado de criação de um ambiente imersivo para o consumo de notícias baseado na tecnologia da realidade virtual que chamamos de Projeto JUMPER.

A própria experiência de trabalhar com desenvolvimento de software, sendo o autor originário da Comunicação, é o eixo principal do texto intitulado TECNOLOGIA DIGITAL APLICADA AO JORNALISMO: relato de experiências com desenvolvimento e aprimoramento de software livre produzido pelo pesquisador Rodrigo Botelho que descreve o estranho, mas ao mesmo tempo desafiador caminho que é operar em equipes multidisciplinares conjugando formações e visões de mundo tão diferentes quanto às que normalmente separam comunicólogos e programadores.

Por fim, ainda nesse bloco, outro relato de experiência intitulado PROCESSO METODOLÓGICO DE CONSTRUÇÃO COLETIVA PARA DESENVOLVER UM CONTEÚDO INTERATIVO PARA TABLETS EM SALA DE AULA, dessa vez em sala de aula, é descrito pela professora Rita Paulino, mostrando como pode ser rica e inspiradora a opção pelo desenvolvimento de produtos para o ambiente digital, no caso considerando as especificidades de entrega de conteúdo em tablets e dispositivos móveis através de uma das suas características mais importantes, a interatividade. Além de descrever esse processo de desenvolvimento, o texto ainda alinha uma metodologia que pode ser utilizada em empreitadas semelhantes.

Outros aspectos da interseção entre mudanças tecnológicas, culturais e econômicas geradas pelo ambiente digital também são explorados no dossiê. $O$ tema principal das narrativas ficcionais é o pano de fundo para o texto sobre Games e Literatura proposto pela professora Naiara Sales Araújo, intitulado VIDEO GAMES E LITERATURA: Do Nimrod à Neuromancer. A partir de uma análise histórica da relação entre essas duas formas de expressão, a pesquisadora traça parâmetros para compreender a centralidade cada vez maior dos games no mundo 


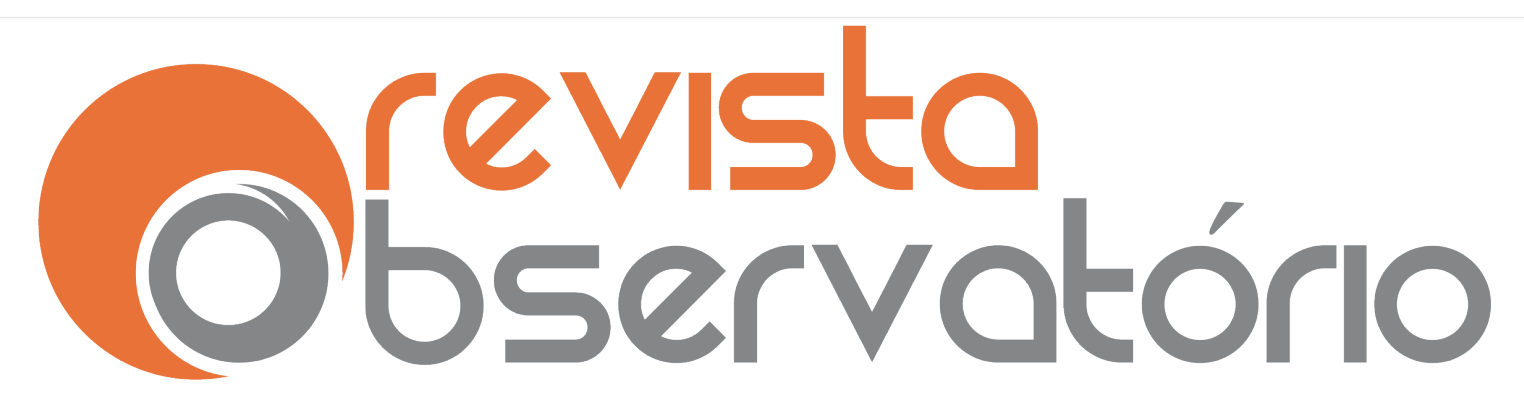

ISSN n० 2447-4266

Vol. 3, n. 3, Maio. 2017

DOI: http://dx.doi.org/10.20873/uft.2447-4266.2017v3n3p24

contemporâneo e sua forma específica de nos levar para mundos diegéticos onde a interação e a imersão assumem novos contornos.

Centrado em narrativas audiovisuais e seu potencial transmídia, os professores João Massarolo e Dario de Souza Mesquita Junior, no texto intitulado CENTROS TRANSMÍDIA E STARTUP AUDIOVISUAL, nos trazem uma reflexão sobre uma indústria que também passa por acentuadas mudanças e apontam novas estruturas para organizar o processo produtivo e orientálo para a inovação.

Por fim, depois desse exemplo sobre as questões econômicas impactadas pelas peculiaridades do digital, o artigo intitulado O MODELO DE POLÍTICA PARA SOCIEDADE DA INFORMAÇÃO DO BRASIL, de Benedito Medeiros nos traz uma análise sobre a política nacional voltada para as questões das tecnologias da informação, demonstrando como é multifacetada a relação entre tecnologia e sociedade e como diretrizes aparentemente corretas podem não atingir todos os objetivos a que se propõem quando o ambiente é complexo e está em acelerada transformação.

Na seção ARTIGOS LIVRES, começamos com o artigo JORNALISMO BASEADO EM LOCALIZAÇÃO: O caso do Breaking News, de Lucas Santiago Arraes Reino e Eduardo Campos Pellanda. Nele os autores discutem o consumo de notícias em cibermeios partindo do filtro da localização geográfica da pessoa, como uma nova possibilidade criada pelos Sistemas Baseados em Localização, que reúnem o acesso à internet, os sistemas de posição geográfica e tecnologias de dispositivos de comunicação móvel.

Em A NARRATIVA JORNALÍSTICA COMO FORMA DE APREENSÃO DO REAL: uma análise da reportagem especial Últimos desejos, do jornal Zero Hora, Cristiane Lindemann discute a narrativa jornalística para além da modalidade textual ou dos gêneros jornalísticos, considerando-a como uma forma de apreensão do mundo capaz de dar sentido a ele. Para isso utiliza a análise 


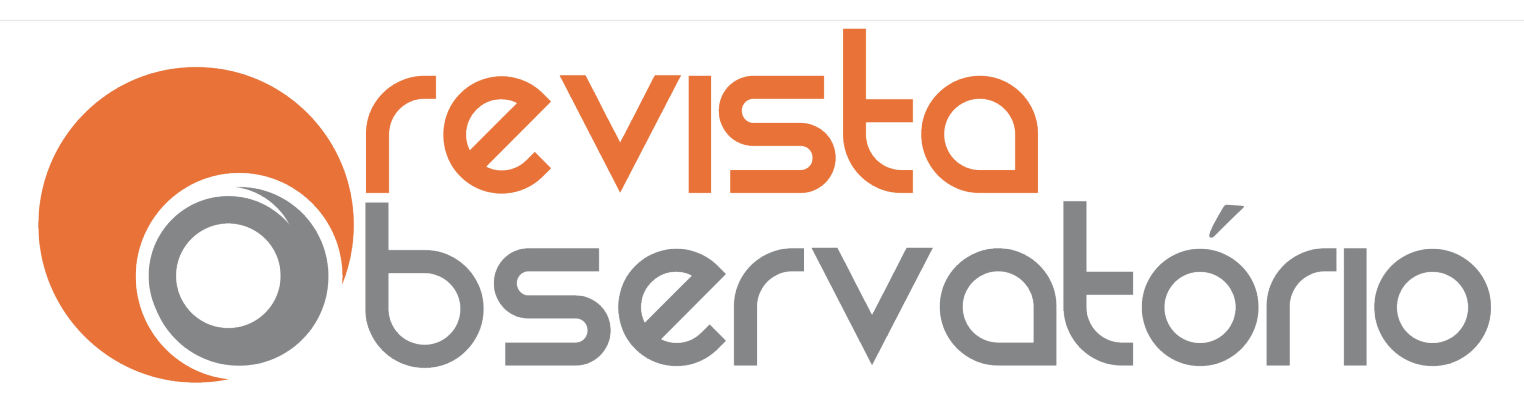

ISSN n० 2447-4266

Vol. 3, n. 3, Maio. 2017

DOI: http://dx.doi.org/10.20873/uft.2447-4266.2017v3n3p24

pragmática, desvendando as estratégias argumentativas utilizadas na reportagem especial intitulada Últimos desejos, publicada no jornal Zero Hora.

No artigo PROCESSOS DE CONVERGÊNCIA DIGITAL E ESTRATÉGIAS MIDIÁTICAS NA CRIAÇÃO DE VALOR: um estudo da Revista Exame, Egle Müller Spinelli e Mariana Benvenido discorrem sobre os conceitos de convergência digital e criação de valor para aplicá-los no caso da Revista Exame, um exemplo de reestruturação de lógica comunicacional a partir do desenvolvimento de novas ferramentas e plataformas para impulsionar o consumo de seus produtos.

Gabriela da Silva Zago em RESSIGNIFICAÇÕES DO ACONTECIMENTO NO JORNALISMO EM REDE aborda as possíveis ressignificações do acontecimento no jornalismo em rede. Para tanto, tweets sobre acontecimentos relacionados à Copa do Mundo de 2014 são utilizados como recorte, em caráter ilustrativo. Resultados apontam para um papel ativo de participação dos usuários na circulação de conteúdos, atuando não apenas no espalhamento da informação, como também atribuindo novos sentidos aos acontecimentos que, ao recircularem, são reconstruídos.

Já no artigo O QUE FAZEM O COMMUNITY MANAGER E O EDITOR DE MÍDIAS SOCIAIS EM DOIS VEÍCULOS DE REFERÊNCIA: ciberjornalismo ou marketing?, Giovana Borges Mesquita discorre sobre novas funções que reúnem atribuições do campo jornalístico e do marketing, mudando a rotina jornalística e levando a questionamentos importantes sobre quais são os valores que norteiam os jornalistas nos processos de seleção, apuração e edição pós redes sociais.

Em DESAFIOS DE UMA PESQUISA INTERNACIONAL: adaptações e inovações a partir de um olhar periférico para o cosmopolitismo, os autores Wilson Roberto Bekesas, Viviane Riegel e Joana Angélica Pellerano desenvolvem uma discussão acerca da experiência com a pesquisa "Cosmopolitismos Juvenis no Brasil", parte constituinte do projeto internacional "Cultures Juveniles à l' ère de la globalization", que visa desenvolver um estudo comparativo em cidades 


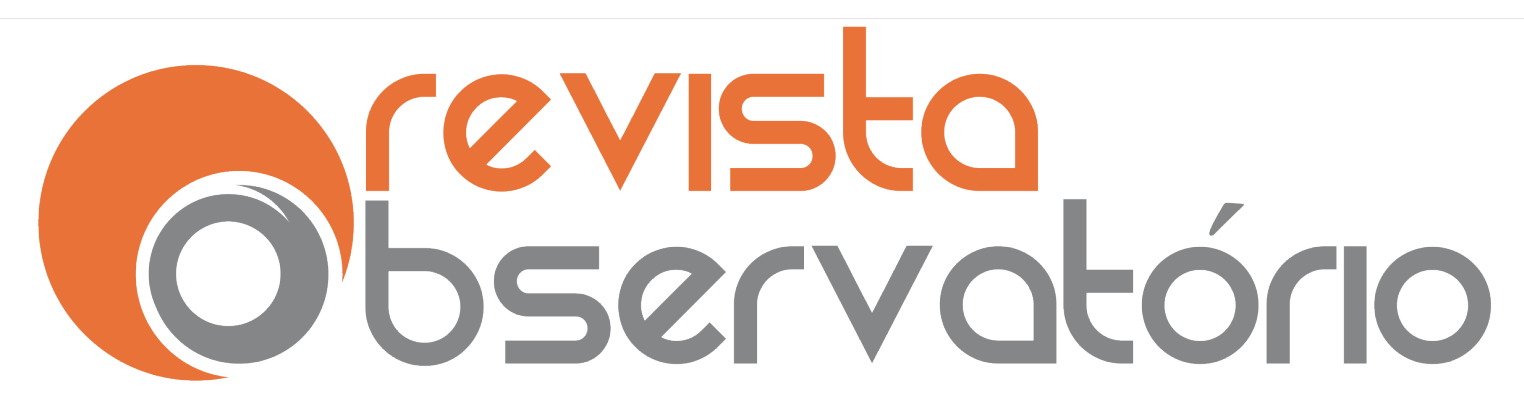

ISSN n 2447-4266

Vol. 3, n. 3, Maio. 2017

DOI: http://dx.doi.org/10.20873/uft.2447-4266.2017v3n3p24

globais para discutir como os jovens constroem representações de si mesmos e de suas relações com o mundo, através do consumo de bens culturais globais ou locais.

No artigo A ORIGEM DO UNIVERSO E OS MITOS SONOROS, Marcos Júlio Sergl foca no evento acústico como parte de todos os momentos da vida da espécie humana. $O$ autor analisa a interrelação entre memória, mito, consumo, gestos sonoros inaugurais e simbolismo, oralmente expressos nos mitos cosmogônicos, responsáveis pela origem do universo.

\section{Em JORNALISMO ESPORTIVO NOS CURSOS DE JORNALISMO DE UNIVERSIDADES}

BRASILEIRAS, Daniel Perdigão examina de perto a questão do Jornalismo Esportivo como disciplina da formação do jornalista, analisando, em pesquisa documental, as matrizes curriculares de 15 cursos entre os mais bem avaliados do país, em busca de conteúdos de Jornalismo Esportivo. Observou-se que somente 10 deles possuem alguma abordagem de Jornalismo Especializado, e apenas 5 têm disciplinas na área do Jornalismo Esportivo.

Já em A PUBLICIDADE NO CONTEXTO DA SOCIEDADE DA SENSAÇÃO: um formato comunicacional e a relação percepção/cognição em foco, Maria Ogécia Drigo reflete sobre a cognição em meio a um contexto permeado por choques audiovisuais e no qual as representações visuais estão incessantemente em cena. Para tanto, consideram-se as transformações da relação percepção/sensação no contexto da sociedade da sensação, na perspectiva de Christoph Türcke, bem como conceitos da arquitetura filosófica de Charles Sanders Peirce.

Em A FESTIVALIZAÇÃO DA CULTURA E A SOCIEDADE, Flávio Lins Rodrigues e Maria Helena Carmo dos Santos abordam a multiplicação dos festivais em cidades de diversas partes do globo e a ampliação dos temas que estes abordam, consolidando-se como potentes instrumentos de comunicação. Salientam a busca do público por novas experiências, emoções e conhecimento, indo ao encontro da necessidade de reinvenção de lugares afetados pela desindustrialização e 


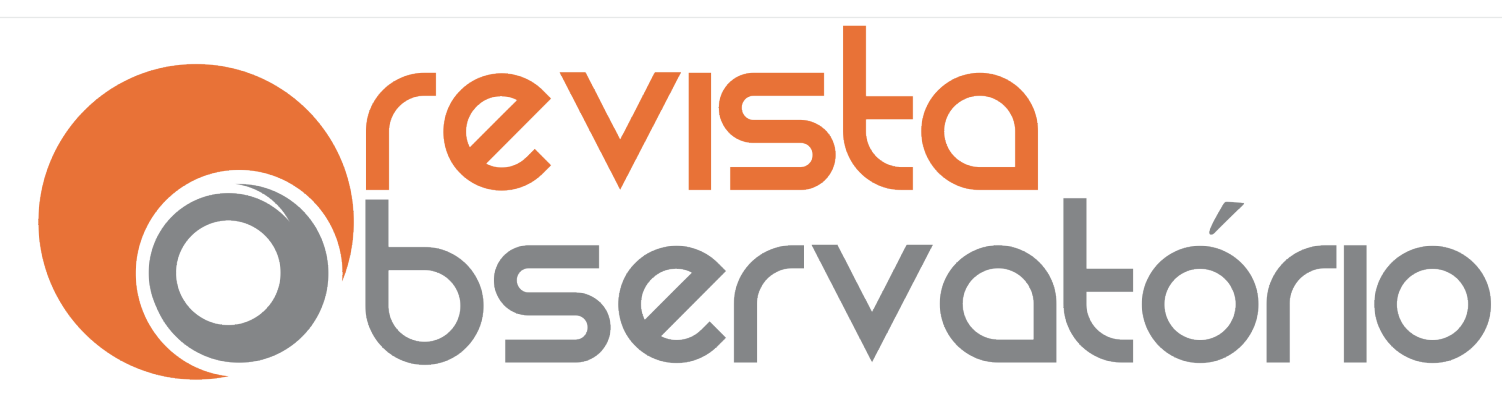

ISSN n² 2447-4266

Vol. 3, n. 3, Maio. 2017

DOI: http://dx.doi.org/10.20873/uft.2447-4266.2017v3n3p24

pela desocupação, que encontraram nos festivais a oportunidade de obter - ou recuperar - seu vigor econômico e cultural.

Maria Ignês Carlos Magno no artigo intitulado QUANDO O BRASIL FICCIONAL FAZ PENSAR O BRASIL REAL. Como a crítica entra nessa história?, tenta compreender no âmbito da linguagem crítica que relações podemos estabelecer entre a crítica de telenovela com as discussões históricas que ocorriam no Brasil nos anos 1970. A crítica é entendida como parte do processo social e atividade teórica que ao veicular os pensamentos e reflexões sobre televisão e telenovela, exerce uma função cultural e histórica.

Em LAS COMPETENCIAS BÁSICAS SE PUEDEN DESARROLLAR A TRAVÉS DE LA MODALIDAD DUAL EN UN LICEO TÉCNICO PROFESIONAL DE ALTA VULNERABILIDAD, José Manuel Salum Tomé apresneta o modelo Dual Mode como um compromisso do Ministério da Educação do Chile para melhorar a formação profissional. A mudança envolveu uma inovação curricular em torno do desenvolvimento de competências centrais, onde, além do ensino e da sala de aula tradicional, frequentam outros agentes e outros cenários que compartilham o trabalho de ensino.

No artigo TRABALHADORAS DO SEXO NA SÉRIE DA HBO, O NEGÓCIO. Representações e a Prostituição de Luxo, Plábio Marcos Martins Desidério e Lailson Costa Duarte buscam compreender as representações da prostituição de luxo, a partir de uma produção televisiva: a série O Negócio, produzida pela HBO. Esta série suscita questões sobre as trabalhadoras do sexo, e, portanto, buscamos analisar alguns discursos e representações dessas mulheres como garotas de programa numa série de televisão.

Em DO QUADRO NEGRO AO TABLET: desafios da docência na era digital, Bento Duarte da Silva, Elaine Jesus Alves e Isabel Cristina Auler Pereira contextualizam o cenário contemporâneo 


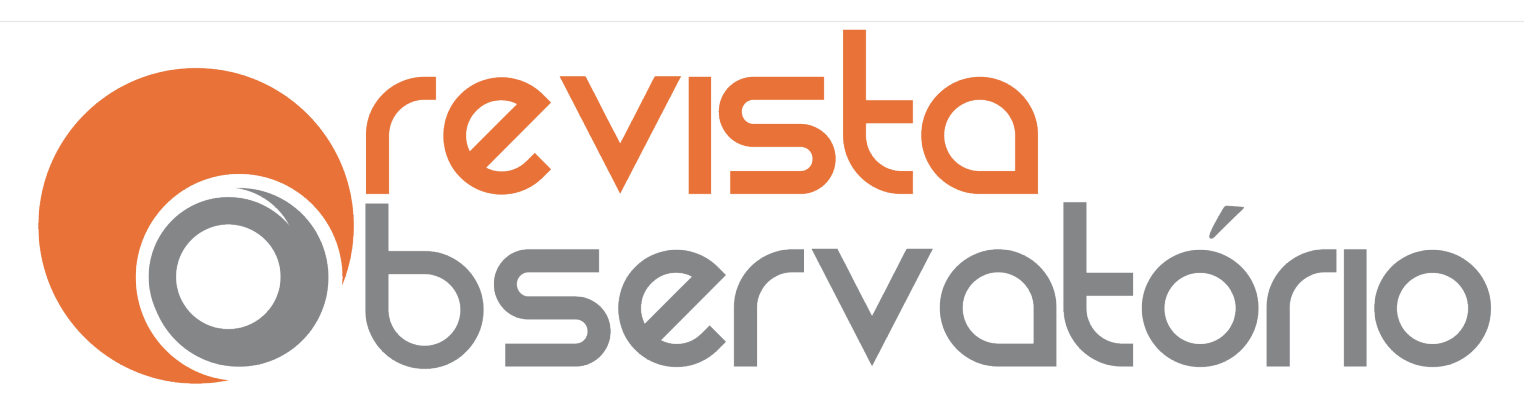

ISSN n० 2447-4266

Vol. 3, n. 3, Maio. 2017

DOI: http://dx.doi.org/10.20873/uft.2447-4266.2017v3n3p24

de ampla difusão e uso das tecnologias no cotidiano dos jovens e ao mesmo tempo faz uma analogia da introdução do quadro-negro e do tablet na escola. Apresenta dados coletados numa pesquisa realizada com professores da rede pública que reforçam a necessidade da formação docente para a literacia digital com foco na aprendizagem online.

No artigo EDUCAÇÃO EM SAÚDE NA EDUCAÇÃO INFANTIL: o contexto da prática docente, Eduardo José Cezari e Roger Trindade Pereira identificam e analisam como docentes abordam a saúde em quatro instituições de Educação Infantil do município de Palmas, estado do Tocantins.

Encerrando a seção, temos o artigo intitulado O PLANO DE CARREIRA DOS TÉCNICOS ADMINISTRATIVOS DE UNIVERSIDADES FEDERAIS: o caso de uma Universidade Federal do norte do Brasil, onde Ana Lúcia Medeiros, Erica Lissandra Bertolossi Dantas e Mônica Aparecida da Rocha Silva discorrem sobre a percepção dos técnicos administrativos sobre a política de capacitação, qualificação e treinamento de uma universidade federal do Norte do Brasil. A metodologia adotada foi a de estudo de caso, com abordagem qualitativa e quantitativa.

E, por fim, na seção ENTREVISTAS, Marco Antônio Gehlen, Lucas Santiago Arraes Reino e Thaisa Cristina Bueno nos brindam com uma entrevista com Elias Machado, intitulada ELIAS MACHADO DISCUTE A FORMAÇÃO DO DOCENTE E DO ESTUDANTE DE JORNALISMO NA CONTEMPORANEIDADE. Machado aproveita a conversa para debater, ainda, as implicações que as novas diretrizes do curso, discutidas e implementadas em todas as universidades do país, podem acarretar à carreira, bem como os dilemas sobre prática e teoria, produção laboratorial e formação de professores, entre outras dicotomias que afligem quem trabalha com comunicação social, seja no mercado, na pesquisa ou na sala de aula.

Esperamos que essa pequena seleção de trabalhos que trazem representantes de todas as regiões do país sem exceção e de diversas instituições de ensino e grupos de pesquisa possam ilustrar o enorme potencial científico representado pelas novas pontes de contato entre 


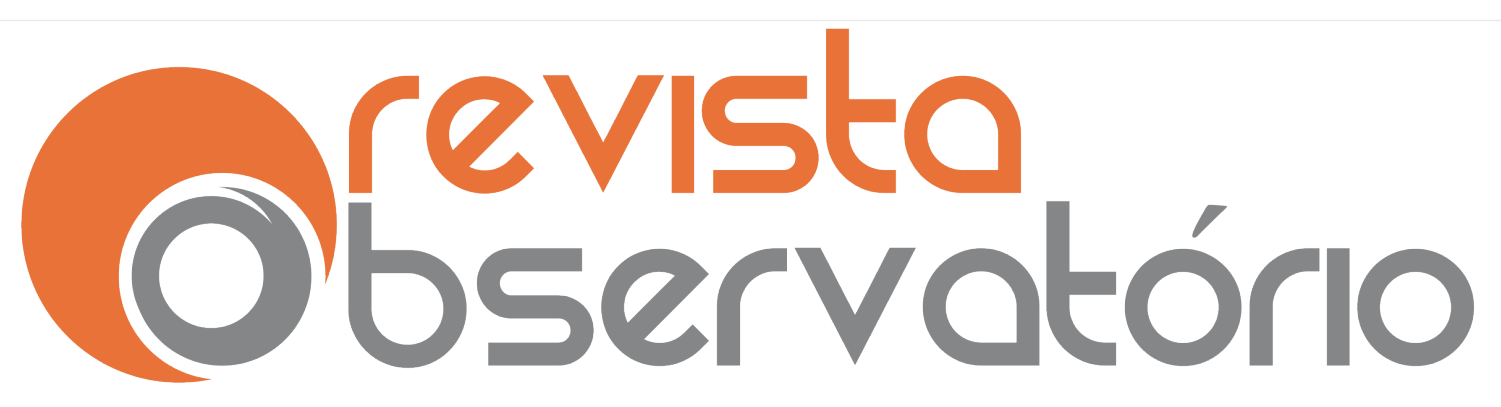

ISSN n² 2447-4266

Vol. 3, n. 3, Maio. 2017

DOI: http://dx.doi.org/10.20873/uft.2447-4266.2017v3n3p24

Comunicação, Ciências Sociais, Humanidades e campos de conhecimento tradicionalmente mais ligados às Ciências Exatas e à Tecnologia. Desejamos boa leitura a todos os interessados.

São Luiz-MA, Palmas-TO, Maio de 2017.

Editor Convidado / Guest Editor / editor invitado Márcio Carneiro dos Santos, Laboratório de Convergência de Mídias - LABCOM/Universidade Federal do Maranhão (UFMA), Brasil.

Editor Geral / Chief Editor / Editor general Francisco Gilson Rebouças Porto Junior, Universidade Federal do Tocantins (UFT), Brasil.

\section{Referências}

ARAÚJO, N. S. VIDEO GAMES E LITERATURA: Do Nimrod à Neuromancer. Revista Observatório , v. 3, n. 3, p. 164-180, 1 maio 2017.

BEKESAS, W. R.; RIEGEL, V.; PELLERANO, J. A. DESAFIOS DE UMA PESQUISA INTERNACIONAL: adaptações e inovações a partir de um olhar periférico para o cosmopolitismo. Revista Observatório , v. 3, n. 3, p. 346-369, 1 maio 2017.

BOTELHO-FRANCISCO, R. E. TECNOLOGIA DIGITAL APLICADA AO JORNALISMO: relato de experiências com desenvolvimento e aprimoramento de software livre. Revista Observatório , v. 3, n. 3, p. 113-138, 1 maio 2017.

CARLOS MAGNO, M. I. QUANDO O BRASIL FICCIONAL FAZ PENSAR O BRASIL REAL. Como a crítica entra nessa história?. Revista Observatório, v. 3, n. 3, p. 459-478, 1 maio 2017.

CARREIRA, K.; SQUIRRA, S. JORNALISMO AUTOMATIZADO, GERAÇÃO DE LINGUAGEM NATURAL E A LÓGICA DO BOM SUFICIENTE. Revista Observatório, v. 3, n. 3, p. 60-84, 1 maio 2017.

CEZARI, E. J.; PEREIRA, R. T. EDUCAÇÃO EM SAÚDE NA EDUCAÇÃO INFANTIL: o contexto da prática docente. Revista Observatório , v. 3, n. 3, p. 561-583, 1 maio 2017.

DESIDÉRIO, P. M. M.; DUARTE, L. TRABALHADORAS DO SEXO NA SÉRIE DA HBO, O NEGÓCIO: Representações e a Prostituição de Luxo. Revista Observatório, v. 3, n. 3, p. 506-531, 1 maio 2017.

DRIGO, M. O. A PUBLICIDADE NO CONTEXTO DA SOCIEDADE DA SENSAÇÃO: um formato comunicacional e a relação percepção/cognição em foco. Revista Observatório , v. 3, n. 3, p. 415-440, 8 abr. 2017.

GEHLEN, M. A.; REINO, L. S. A.; BUENO, T. C. ELIAS MACHADO DISCUTE A FORMAÇÃO DO DOCENTE E DO ESTUDANTE DE JORNALISMO NA CONTEMPORANEIDADE. Revista Observatório , v. 3, n. 3, p. 619-633, 1 maio 2017.

LIMA JUNIOR, W. T. DESAFIOS DO JORNALISMO EM AMBIENTE COMUNICACIONAL SIMBIÓTICO ESTRUTURADO PELA COMPUTAÇÃO COGNITIVA. Revista Observatório , v. 3, n. 3, p. 34-59, 1 maio 2017.

LINDEMANN, C. La A NARRATIVA JORNALÍSTICA COMO FORMA DE APREENSÃO DO REAL: uma análise da reportagem especial Últimos desejos, do jornal Zero Hora. Revista Observatório, v. 3, n. 3, p. 261-284, 1 maio 2017. 


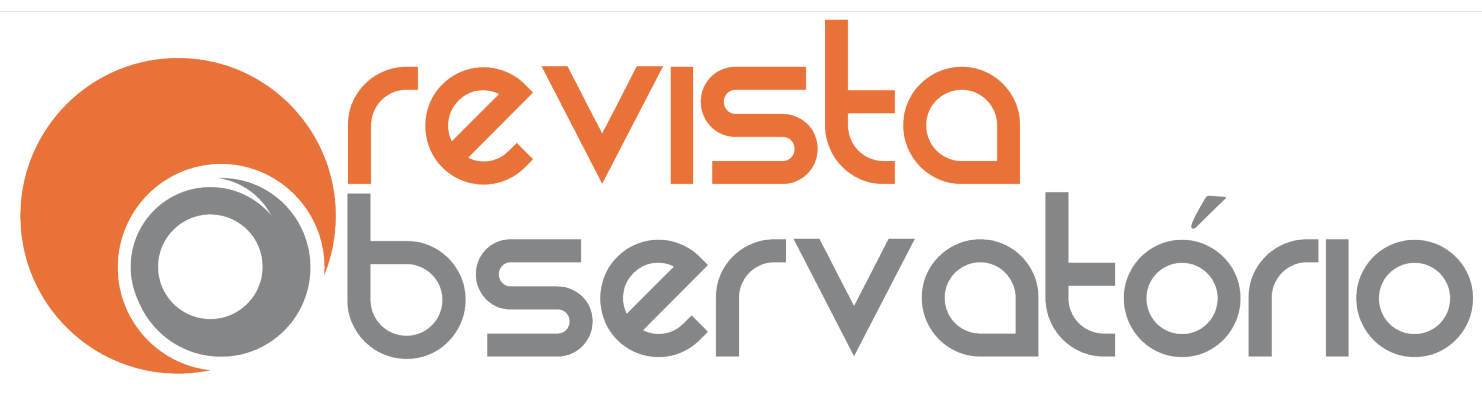

ISSN n² 2447-4266

Vol. 3, n. 3, Maio. 2017

DOI: http://dx.doi.org/10.20873/uft.2447-4266.2017v3n3p24

MASSAROLO, J.; MESQUITA, D. CENTROS TRANSMÍDIA E STARTUP AUDIOVISUAL. Revista Observatório, v. 3, n. 3, p. 181-206, 1 maio 2017.

MEDEIROS NETO, B. O MODELO DE POLÍTICA PARA SOCIEDADE DA INFORMAÇÃO DO BRASIL. Revista Observatório, v. 3, n. 3, p. 207-228, 1 maio 2017.

MEDEIROS, A. L.; DANTAS, E. L. B.; SILVA, M. A. DA R. O PLANO DE CARREIRA DOS TÉCNICOS ADMINISTRATIVOS DE UNIVERSIDADES FEDERAIS: o caso de uma Universidade Federal do norte do Brasil. Revista Observatório , v. 3, n. 3, p. 584-618, 1 maio 2017.

MESQUITA, G. B. O QUE FAZEM O COMMUNITY MANAGER E O EDITOR DE MÍDIAS SOCIAIS EM DOIS VEÍCULOS DE REFERÊNCIA: ciberjornalismo ou marketing?. Revista Observatório, v. 3, n. 3, p. 327-345, 1 maio 2017.

PAULINO, R. DE C. R. PROCESSO METODOLÓGICO DE CONSTRUÇÃO COLETIVA PARA DESENVOLVER UM CONTEÚDO INTERATIVO PARA TABLETS EM SALA DE AULA. Revista Observatório , v. 3, n. 3, p. 139-163, 1 maio 2017. PERDIGÃO, D. JORNALISMO ESPORTIVO NOS CURSOS DE JORNALISMO DE UNIVERSIDADES BRASILEIRAS. Revista Observatório , v. 3, n. 3, p. 390-414, 1 maio 2017.

REINO, L. S. A.; PELLANDA, E. C. JORNALISMO BASEADO EM LOCALIZAÇÃO: O caso do Breaking News. Revista Observatório , v. 3, n. 3, p. 229-260, 1 maio 2017.

RODRIGUES, F. L.; DOS SANTOS, M. H. C. A FESTIVALIZAÇÃO DA CULTURA E A SOCIEDADE. Revista Observatório, v. 3, n. 3, p. 441-458, 1 maio 2017.

SANTOS, M. C. DOS. INTERNET DAS COISAS E SISTEMAS INTELIGENTES NO JORNALISMO: Explorando novas formas narrativas para reinventar a percepção de valor das novas gerações. Revista Observatório , v. 3, n. 3, p. 85-112, 1 maio 2017.

SERGL, M. J. A ORIGEM DO UNIVERSO E OS MITOS SONOROS. Revista Observatório , v. 3, n. 3, p. 370-389, 1 maio 2017.

SILVA, B. D. DA; ALVES, E. J.; PEREIRA, I. C. A. DO QUADRO NEGRO AO TABLET: Desafios da docência na era digital. Revista Observatório , v. 3, n. 3, p. 532-560, 1 maio 2017.

SPINELLI, E. M.; BENVENIDO, M. PROCESSOS DE CONVERGÊNCIA DIGITAL E ESTRATÉGIAS MIDIÁTICAS NA CRIAÇÃO DE VALOR: um estudo da Revista Exame. Revista Observatório , v. 3, n. 3, p. 285-304, 1 maio 2017.

TOMÉ, J. M. S. LAS COMPETENCIAS BÁSICAS SE PUEDEN DESARROLLAR A TRAVÉS DE LA MODALIDAD DUAL EN UN LICEO TÉCNICO PROFESIONAL DE ALTA VULNERABILIDAD. Revista Observatório , v. 3, n. 3, p. 479-505, 1 maio 2017. ZAGO, G. DA S. RESSIGNIFICAÇÕES DO ACONTECIMENTO NO JORNALISMO EM REDE. Revista Observatório , v. 3, n. 3, p. 305-326, 1 maio 2017. 